\title{
Characterisation of immunofluorescent heterophile antibodies which may be confused with autoantibodies
}

\author{
B. R. HAWKINS, B. L. MCDONALD, AND R. L. DAWKINS ${ }^{1}$
}

From the Clinical Immunology Division, Royal Perth.Hospital and Department 'of Clinical Immunology, Perth Medical Centre, Perth, Western Australia

SUMMARY Approximately $6 \%$ of sera submitted for routine immunofluorescent autoantibody screening produced characteristic reaction patterns against a variety of animal and human tissues. It is suggested that these non-tissue-specific patterns represent a complex family of heterophile antibodies which could be confused with certain autoantibodies. It is further suggested that these heterophile antibodies bear a relationship to IgG isohaemagglutinins.

When using animal tissues to screen human sera for tissue-specific autoantibodies there must always be the possibility of false positive reactions due to heterophile antibodies which react with xenospecific and allo-specific rather than tissue-specific antigens. For example, false positive results may be obtained when rat stomach is used to screen human sera for parietal cell autoantibodies (Ireton et al., 1971; Muller et al., 1971; Strickland and Hooper, 1972). Human heterophile antibodies may also react with renal tubule components of rat but not man or mouse (Ireton et al., 1971; Muller et al., 1971). After screening many thousand sera on animal tissues we have demonstrated that sera which stain parietal cells and renal tubular cells of rat but not other species also show apparent sarcolemmal staining of rat heart and produce characteristic reaction patterns on tissues of other species. Preliminary characterisation of these antibodies has been reported previously (Nicholson et al., 1977). The intention of this report is to characterise these heterophile antibodies in more detail and to show that at least some of the immunofluorescent patterns produced could be confused with those produced by various autoantibodies.

${ }^{1}$ Reprint requests to: Dr R. L. Dawkins, Clinical Immunology Division, Royal Perth Hospital, Perth, Western Australia 6000

Received for publication 28 September 1976

\section{Material and methods}

SERA

This report is based on the results of testing over 10000 sera which have been submitted to these Departments for autoantibody screening. The sera were obtained from hospital patients, blood donors, and hospital staff.

\section{IMMUNOFLUORESCENCE}

Frozen sections $(4 \mu)$ were dried in air for 10 minutes and then incubated with serum diluted 1 in 10 in phosphate buffered saline (PBS) for 30 minutes. The sections were then washed in PBS for 10 minutes and covered for 30 minutes with a 1 in 10 dilution of polyvalent sheep anti-human gammaglobulin reagent conjugated with fluorescein isothiocyanate (Wellcome Reagents) or with monospecific anti-immunoglobulin conjugate diluted in accordance with the manufacturer's instructions (Behringwerke). The polyvalent immunoglobulin conjugate was absorbed with rat liver homogenate before use. Finally, the sections were washed for one hour with three changes of PBS and were mounted in $90 \%$ glycerol (pH 8.4). Slides were examined using a Leitz Orthoplan microscope fitted with UG5 and UG1 primary filters and K430 and 460 secondary filters. Photographs were taken with an Orthomat camera using Tri-X film. 


\section{SUBSTRATES}

All sera were screened on composite sections containing mouse stomach and rat heart, liver, kidney, and stomach. In addition, selected sera were tested against human kidney, stomach, skeletal muscle, myocardium, and liver obtained either post mortem or following surgery from individuals of known ABO group. These same sera were also tested against mouse heart and kidney and against guinea-pig skeletal muscle.

\section{Results}

\section{RAT HEART}

The most frequent immunofluorescent pattern attributed to heterophile antibody was the staining of interstitium on rat heart (Fig. 1a). This pattern appeared identical with that described as 'endomysial' by van der Geld (1964) and 'sarcolemmal' by Tagg et al. (1972). The pattern occasionally occurred alone on the composite substrate block.

\section{RAT STOMACH}

The staining was of parietal cells as described by Ireton et al. (1971), Muller et al. (1971), and Strickland and Hooper (1972) and is shown in Figure 1b. Unlike the findings of Strickland and Hooper (1972), the heterophile parietal cell staining was often indistinguishable in intensity from that given by classical antiparietal cell antibody.

\section{RAT KIDNEY}

The antibody stained proximal tubule cells, particularly the brush border (Fig. 2a), and often stained also the tubular basement membrane (Fig. 1c). This pattern was also described by Ireton et al. (1971), Muller et al. (1971), and Strickland and Hooper (1972).

The brush border staining invariably occurred in conjunction with rat gastric parietal cell staining and seldom occurred in the absence of interstitial staining on rat heart.

\section{RAT LIVER}

Heterophile staining of rat liver occurred only in those cases in which strong heterophile reactions were present on rat heart, stomach, and kidney. In such cases, the antibody was associated with blood vessels and Kuppfer cells (Fig. 1d).

\section{MOUSE HEART}

Heterophile staining of mouse heart appeared indistinguishable from the interstitial pattern shown by rat heart (Fig. 1a).

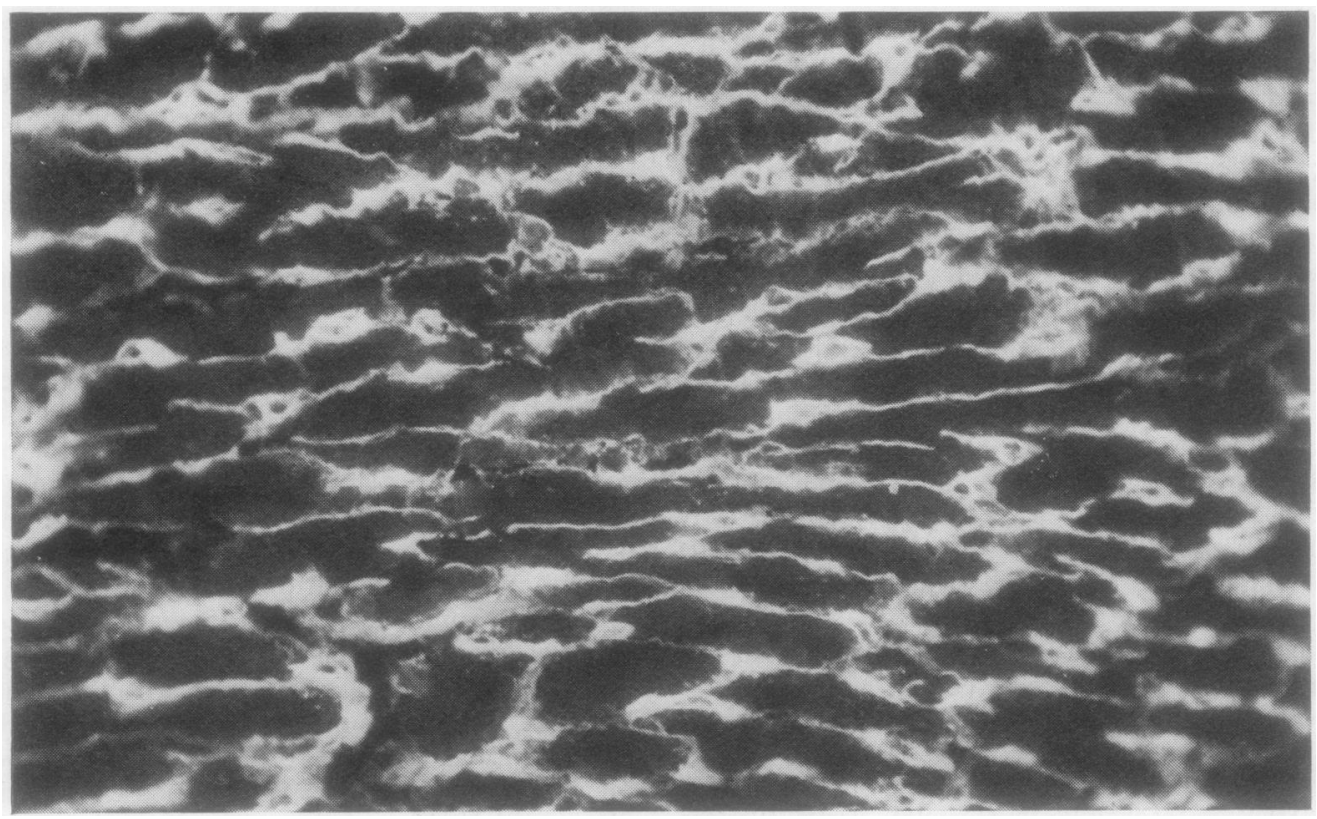

Fig. 1 Classical immunofluorescent heterophile antibody.

(1a) Rat heart interstitium. 


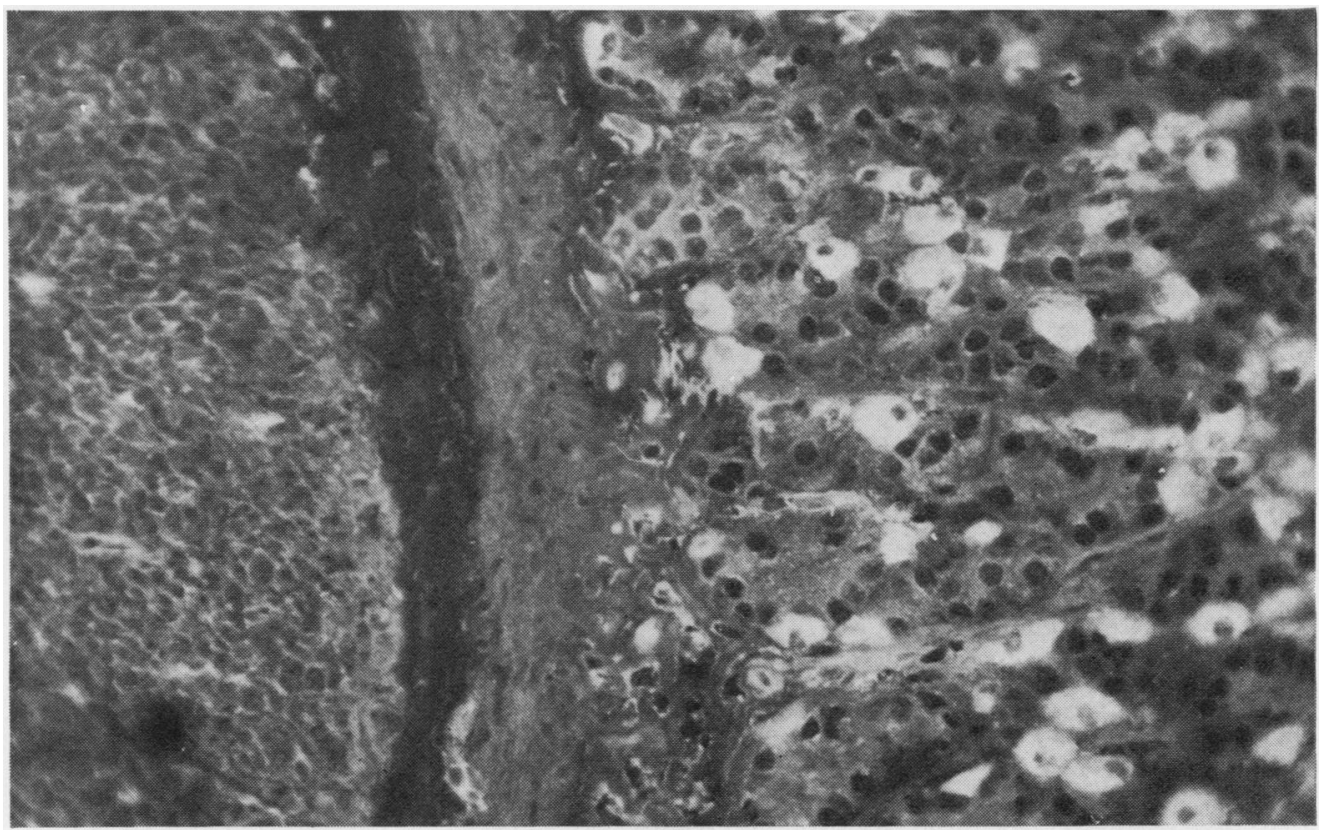

(1b) Rat gastric parietal cells.

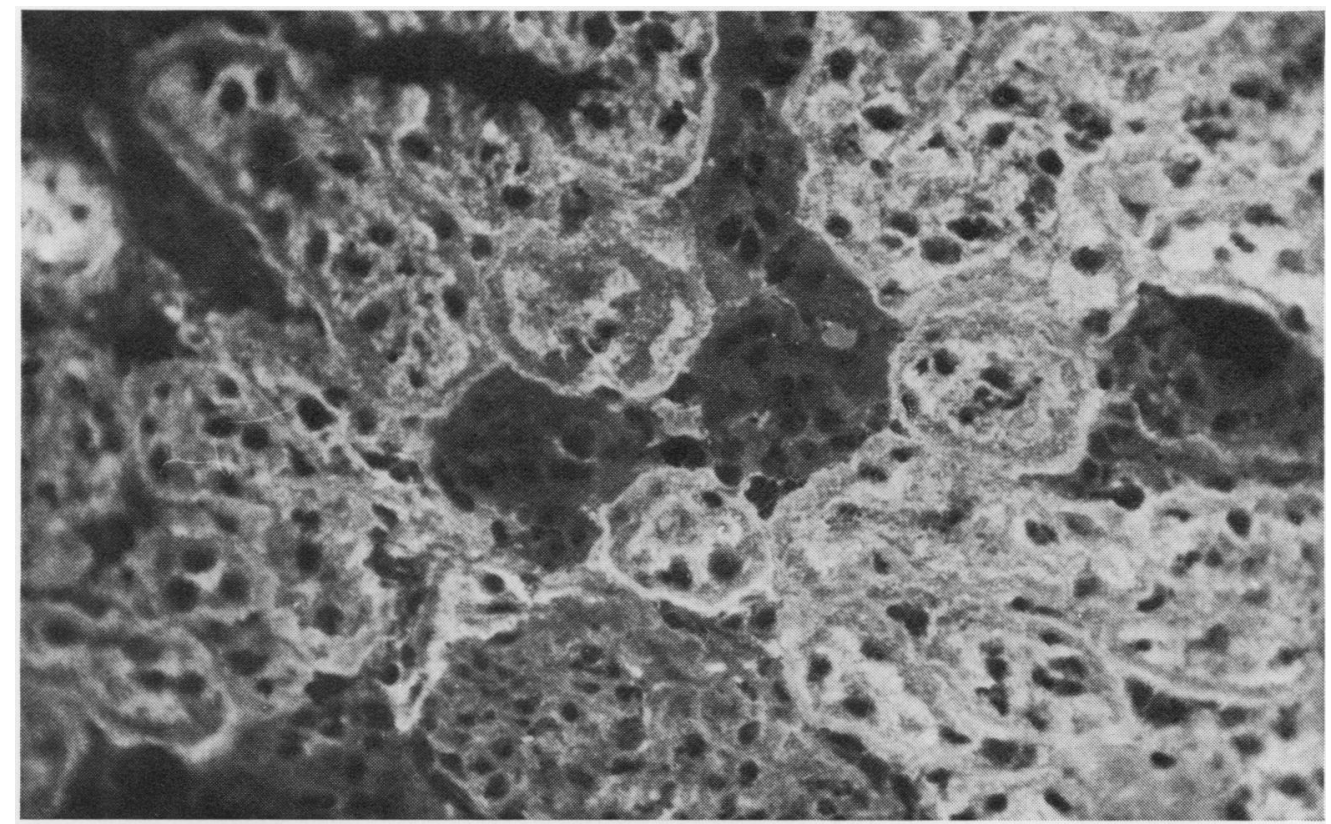

(1c) Proximal convoluted tubular brush border of rat kidney. 
(1d) Kuppfer cells of rat liver.

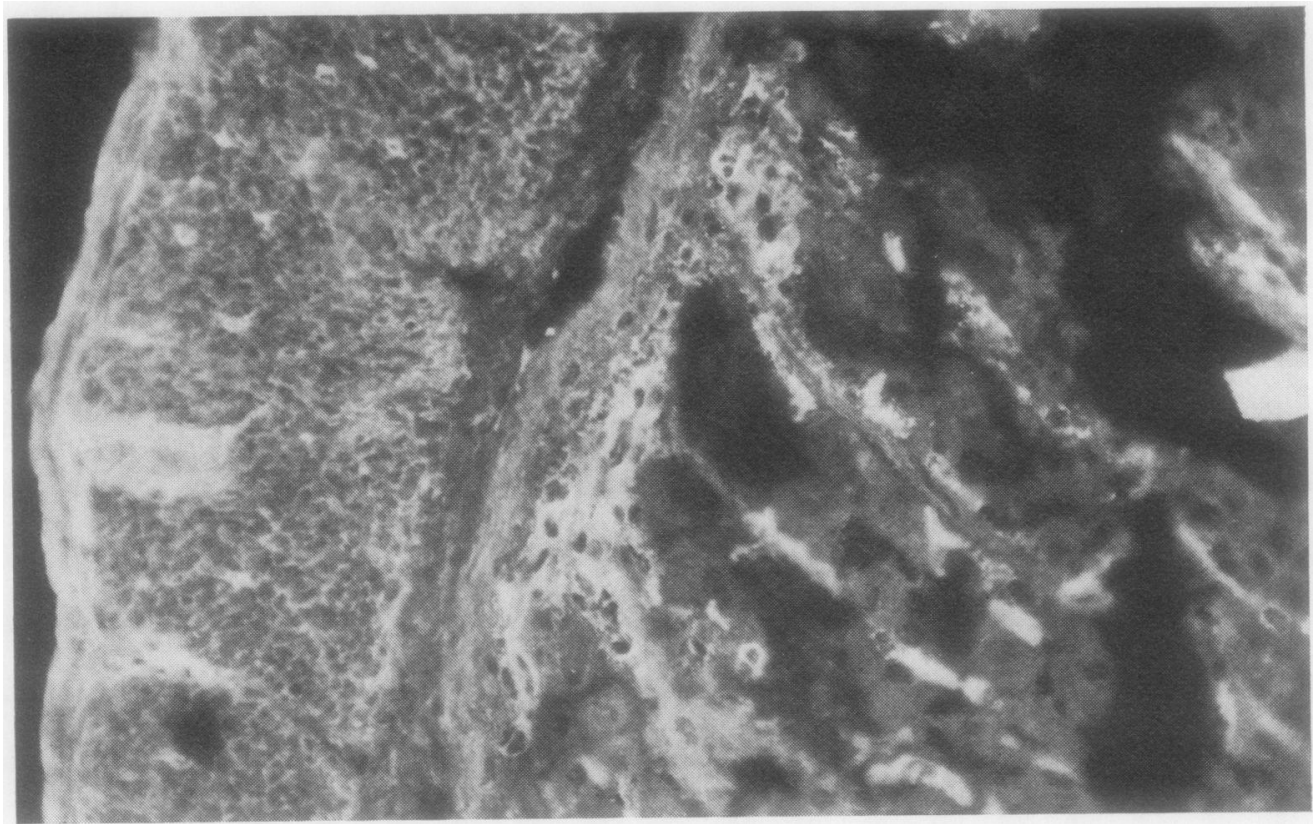

(1e) Smooth muscle interstitium and capillaries of mouse stomach. 


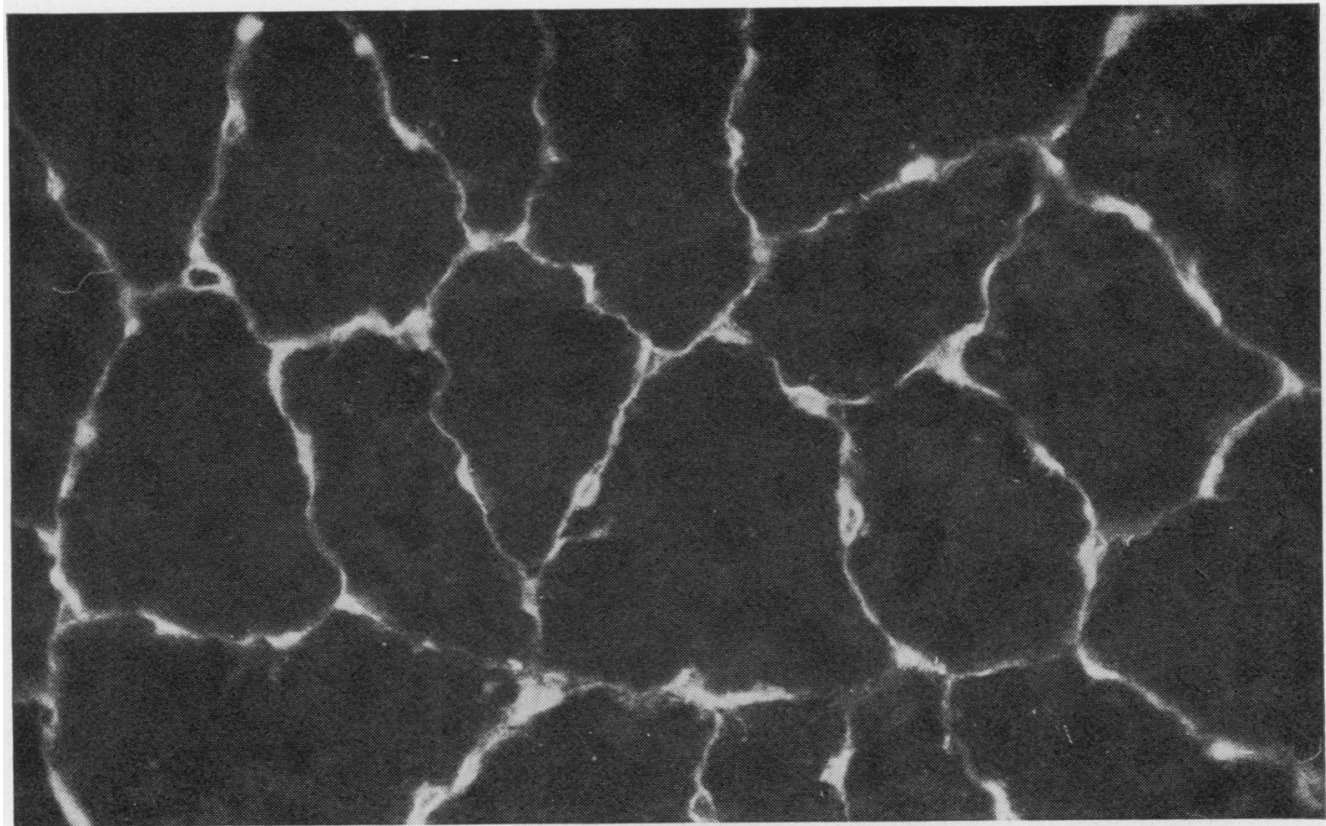

(1f) Endomysium of guinea-pig skeletal muscle.

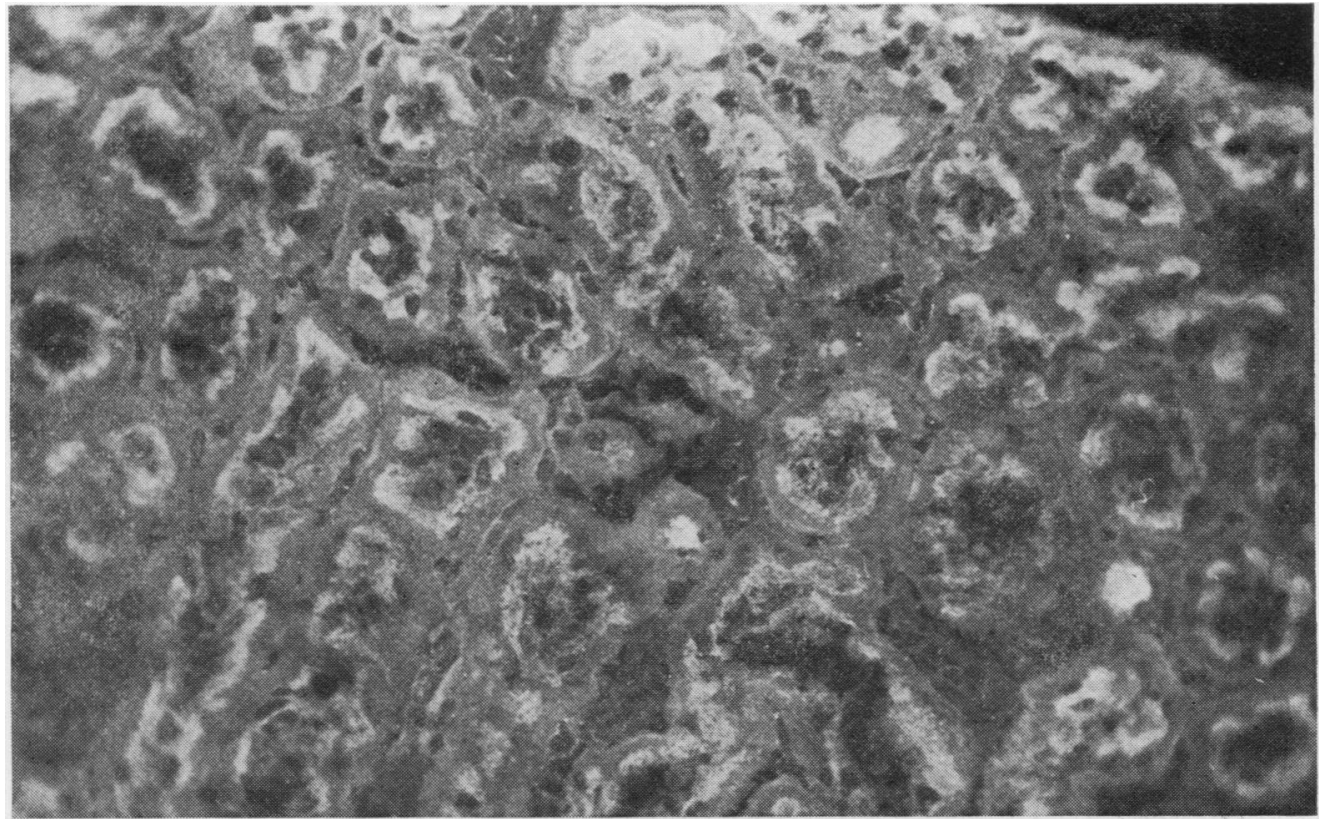

Fig. 2 Immunofluorescent staining patterns of heterophile antibody on kidney of various species.

(2a) Rat kidney without staining of tubular basement membranes. 
(2b) Peritubular vascularity of mouse kidney.

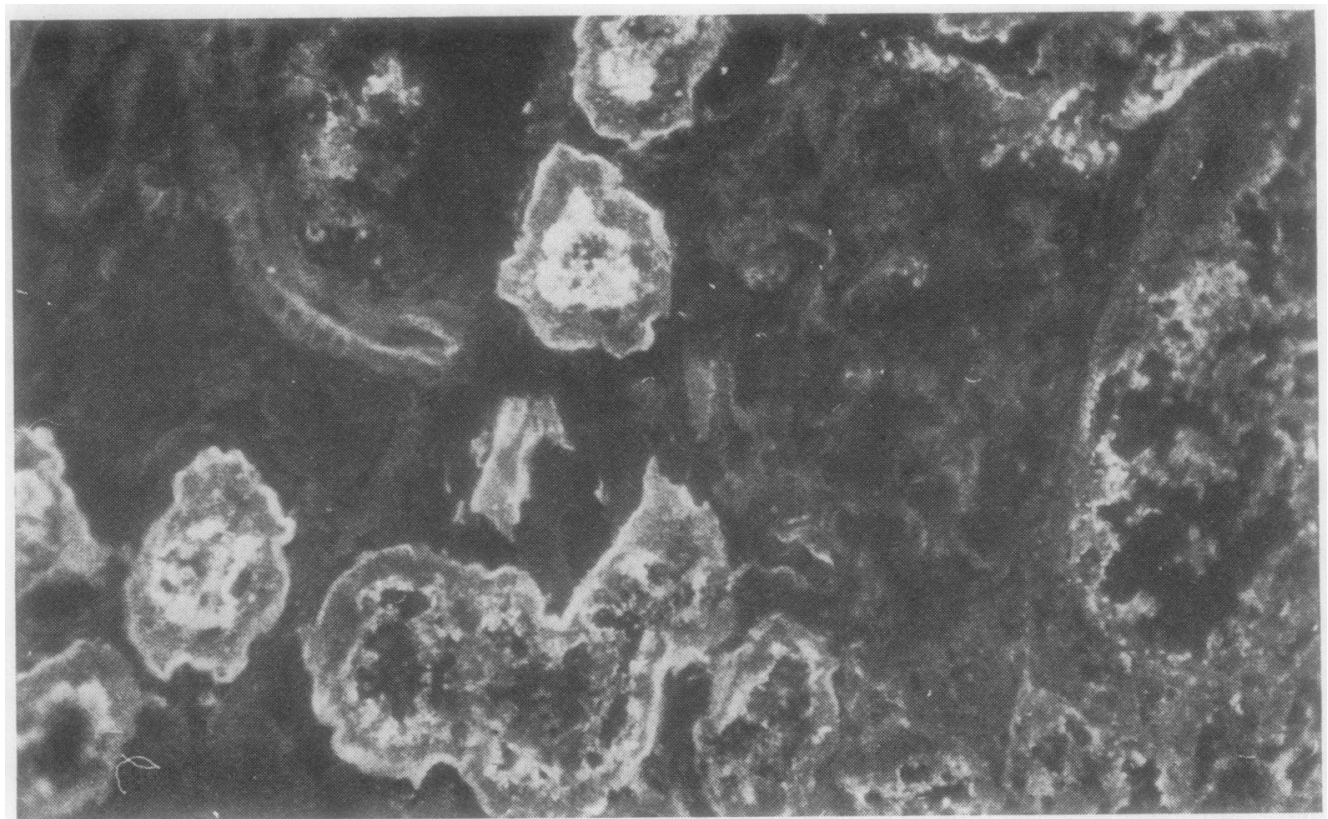

(2c) Proximal tubular brush border and basement membranes of guinea-pig kidney. 


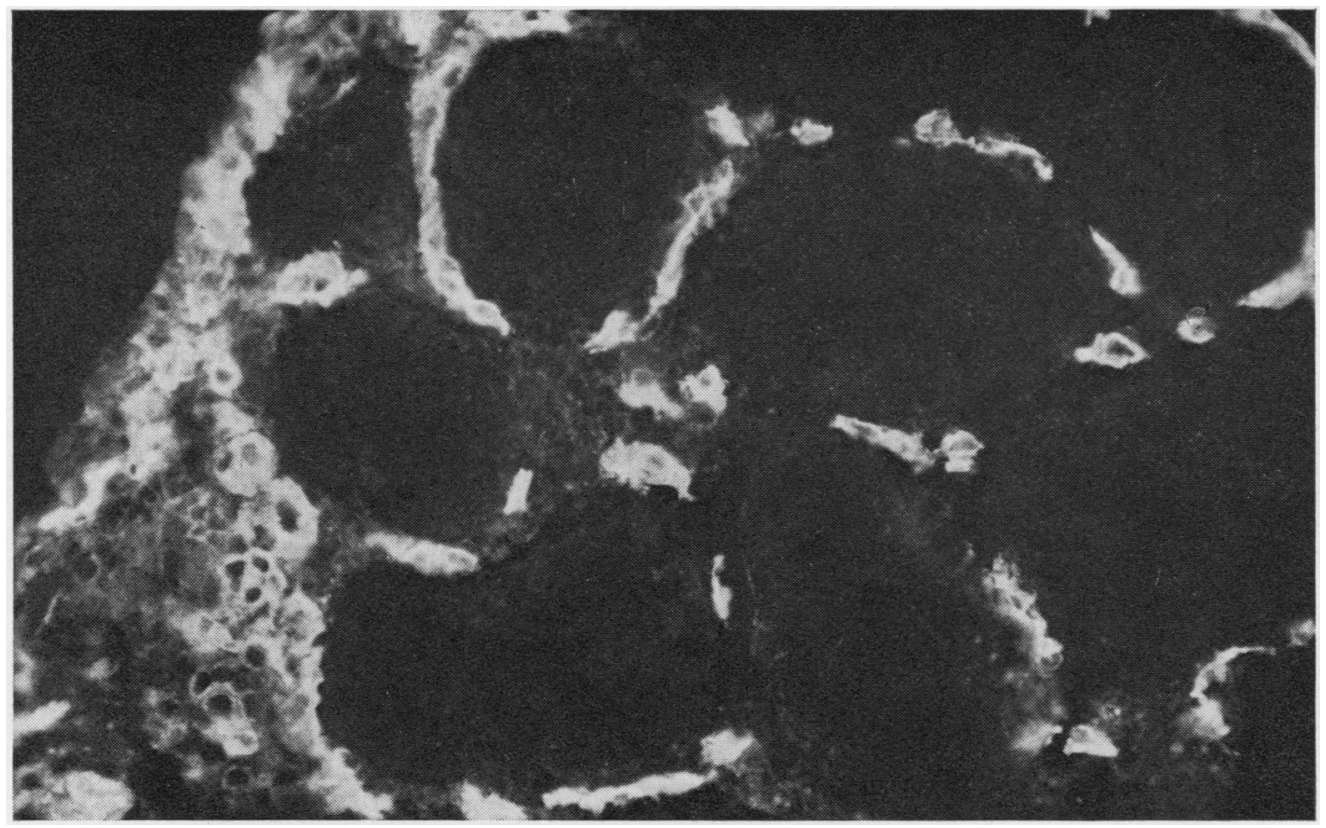

(2d) Peritubular vascularity of human kidney.

\section{MOUSE STOMACH}

The heterophile antibody typically stained the capillaries and smooth muscle interstitium of mouse gastric mucosa (Fig. 1e) but did not stain parietal cells. The pattern was not found in the absence of heterophile staining of rat tissue but neither was it found in all sera which reacted with rat tissue. This staining pattern has been described as 'antivascular antibody' by Person et al. (1974).

\section{MOUSE KIDNEY}

Those sera giving heterophile reactions with rat tissue and mouse stomach also reacted with murine glomerular capillaries and peritubular blood vessels giving the pattern described by Person et al. (1974) (Fig. 2b).

\section{GUINEA-PIG HEART}

The reaction with guinea-pig heart appeared identical with the heart staining of rat (Fig. 1a) and mouse.

\section{GUINEA-PIG KIDNEY}

The staining was of proximal convoluted tubules, particularly the brush border (Fig. 2c), and appeared identical with the pattern shown in rat kidney. As in the case of rat kidney there was no glomerular staining.

\section{GUINEA-PIG SKELETAL MUSCLE}

Heterophile activity on guinea-pig skeletal muscle consisted of staining of the endomysium and small blood vessels without sarcoplasmic staining and is shown in cross section in Figure 1f.

\section{HUMAN TISSUES}

Not all sera giving heterophile reactions with rat, mouse, and guinea-pig tissue reacted with human tissue. Reactions with human tissue seemed to be restricted to those heterophile sera which possessed IgG isohaemagglutinins. In these cases, the antibodies appeared to be reacting with capillary components and the reactions were generally consistent with the descriptions of the distribution of blood group substances in human tissues given by Szulman (1960). The reaction with kidney (Fig. 2d) was similar to the peritubular vascular staining of mouse kidney (Fig. 2a) and included staining of glomerular arterioles and glomerular tufts. Skeletal muscle and cardiac staining (Fig. 3) was characterised by reactions with capillaries. Parietal cell staining was not seen when human stomach was tested with sera containing heterophile antibody.

CLASSICAL IMMUNOFLUORESCENT HETEROPHILE ANTIBODY

We have defined classical immunofluorescent hetero- 


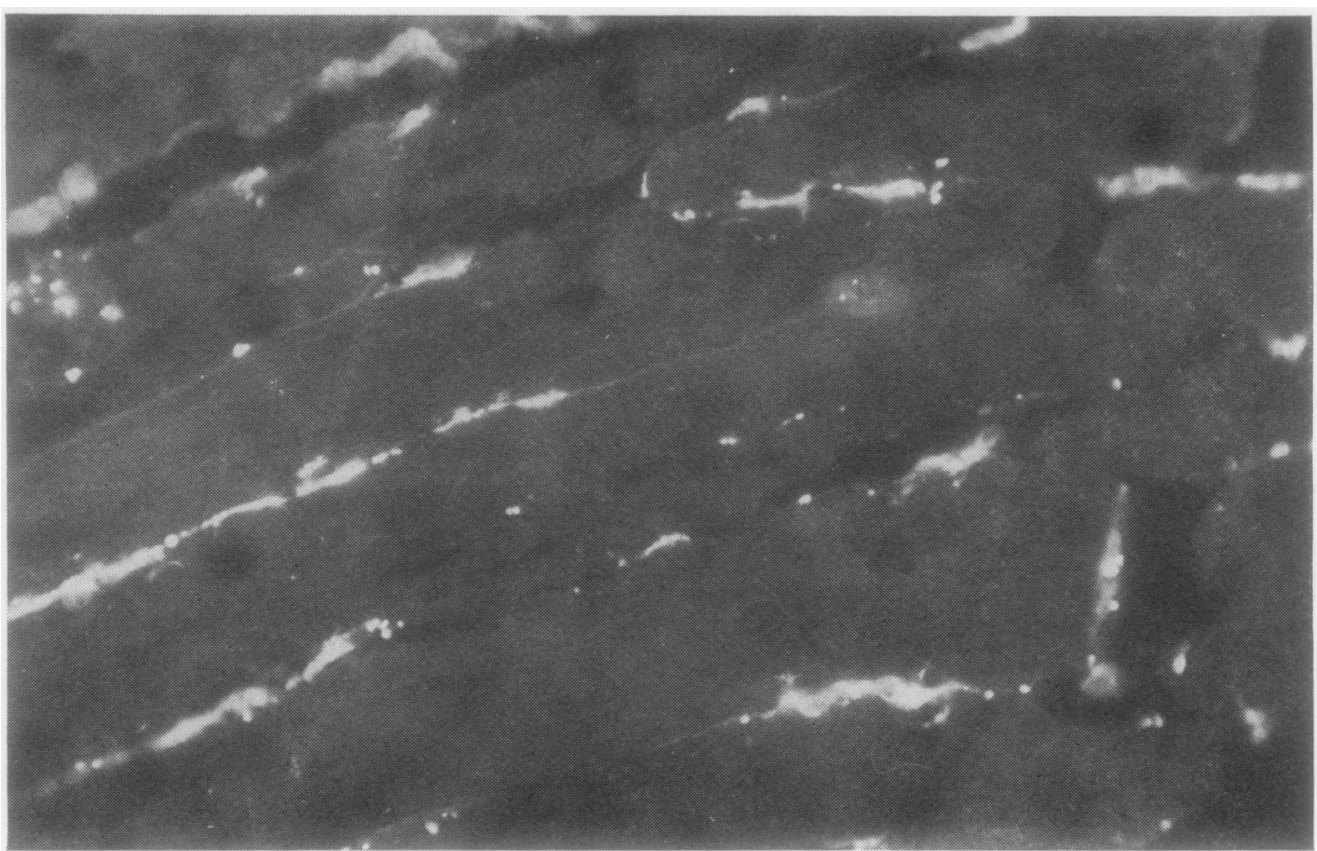

Fig. 3 Capillary staining of human skeletal muscle.

phile antibody largely according to the heterophile reactions seen most frequently on our routine composite substrate block, namely, rat heart interstitium, rat kidney brush border, and rat gastric parietal cells. Confirmatory evidence of heterophile antibody may frequently be provided by the staining of capillaries and smooth muscle interstitium of mouse stomach and occasionally by capillary and Kuppfer cell staining of rat liver. Associated interstitial staining of guinea-pig skeletal muscle provides unequivocal evidence of heterophile antibody. Approximately $6 \%$ of sera submitted for investigation were classified as possessing the classical heterophile pattern. The percentage was higher in samples from individuals with a history of alloimmunisation (McDonald et al., 1977). In all instances the antibodies were found to be of the IgG class.

\section{Discussion}

The data presented here show that human sera may contain antibodies to a variety of non-tissue-specific antigens. We suggest that the various reaction patterns with animal tissue represent a complex family of heterophile antibodies which needs to be taken into consideration to avoid false positive reporting of autoantibodies. Different authors have noted various aspects of the total heterophile reaction pattern and have drawn attention to the possible confusion which can occur with the reaction pattern of particular autoantibodies. Van der Geld (1964) drew attention to endomysial staining in relation to the anti-heart antibodies found in the post-cardiotomy syndrome. Other workers have shown that parietal cells can be stained by heterophile antibodies (Ireton et al., 1971; Muller et al., 1971; Strickland and Hooper, 1972). From the results reported here it is clear that heterophile antibodies could also be $\mathrm{O}$ confused with other autoantibodies. The heterophile pattern on rat liver could be confused with the antireticulin antibody described by Rizzetto and Doniach (1973), and mitochondrial antibody or (Doniach et al., 1966) could be confused with hetero- N phile staining of rat stomach. Similarly, liver/kidney N microsomal antibodies (Doniach, 1974) could be $\bigcirc$ confused with heterophile staining of rat kidney, and smooth muscle antibody (Holborow, 1972) could be $\frac{0}{\Phi}$ confused with heterophile staining of mouse $\stackrel{9}{+}$ stomach. Nicholson et al. (1977) have already drawn 0 attention to the possible confusion between hetero- $\bar{O}$ phile antibody and various types of anti-heart $\overrightarrow{\mathrm{D}}$ antibodies.

Muller et al. (1971) suggested that the problem of $\frac{\varrho}{\sigma}$ false positive parietal cell staining can be avoided by the use of mouse stomach, while Strickland and 
Hooper (1972) recommended the use of human stomach. However, we consider that these do not provide entirely satisfactory solutions. False positive parietal cell staining of rat stomach due to heterophile antibody can easily be replaced by false positive smooth muscle staining if mouse stomach is used in place of rat stomach. Moreover, human tissues can introduce their own problems in that they can contain non-tissue-specific alloantigens which can react with isohaemagglutinins in human sera. Furthermore, we have found animal tissue much more convenient to handle, and we prefer the better standardisation which can be achieved by a plentiful supply of fresh substrate. Since heterophile antibody is not tissue-specific, the problem of falsely attributing autoantibody activity to heterophile activity can largely be overcome if multiple tissues are included in the test substrate. In addition, the patterns described here should allow the recognition of at least the major heterophile reactions which may have clinical significance of their own (McDonald et al., 1977).

During the course of these studies we have found that ABO substances detected in human tissues by immunofluorescence react preferentially, if not exclusively, with IgG rather than IgM isohaemagglutinins. Previous workers have used 'immune' antibodies to detect $\mathrm{ABO}$ substances in tissues without distinguishing between the separate reactivities of IgM and IgG isohaemagglutinins (eg, Glynn et al., 1957; Szulman, 1960; Kaplan et al., 1961). The significance of the different reactions obtained with antibodies of different immunoglobulin classes remains to be established.

This work was supported by grants from the Royal Perth Hospital Research Foundation, the Australian Kidney Foundation, and the Western Australian Arthritis and Rheumatism Foundation. We are grateful to Mrs A. Sharpe for secretarial assistance and to $\mathrm{Mr} \mathrm{H}$. Upenieks for preparing the Figures.

\section{References}

Doniach, D. (1974). Immunofluorescent autoantibody studies in the diagnosis of chronic liver disorders. R.C.
Gastro-ent., 6, 192-203.

Doniach, D., Roitt, I. M., Walker, J. G., and Sherlock, S. (1966). Tissue antibodies in primary biliary cirrhosis, active chronic (lupoid) hepatitis, cryptogenic cirrhosis and other liver diseases and their clinical implications. Clin. exp. Immunol., 1, 237-262.

Glynn, L. E., Holborow, E. J., and Johnson, G. D. (1957). The distribution of blood-group substances in human gastric and duodenal mucosa. Lancet, 2, 1083-1088.

Holborow, E. J. (1972). Smooth-muscle autoantibodies, viral infections and malignant disease. Proc. roy. Soc. Med., 65, 481-484.

Ireton, H. J. C., Muller, H. K., and McGiven, A. R. (1971). Human antibody against rat gastric parietal cells and kidney brush border. Clin. exp. Immunol., 8, 783-789.

Kaplan, M. H., Meyeserian, M., and Kushner, I. (1961). Immunologic studies on heart tissue. IV. Serologic reactions with human heart tissue as revealed by immunofluorescent methods: isoimmune, Wassermann and autoimmune reactions. J. exp. Med., 113, 17-36.

McDonald, B. L., Hawkins, B. R., Dawkins, R. L., and Davey, M. G. (1977). Characterisation of human heterophile antibodies apparently induced by alloimmunisation. Vox Sang., (In press).

Muller, H. K., McGiven, A. R., and Nairn, R. C. (1971). Immunofluorescent staining of rat gastric parietal cells by human antibody unrelated to pernicious anaemia. J. clin. Path., 24, 13-14.

Nicholson, G. C., Dawkins, R. L., McDonald, B. L., and Wetherall, J. D. (1977). A classification of anti-heart antibodies: Differentiation from a heterophile antibody. Clin. Immunol. Immunopath., (In press).

Person, D. A., Leatherwood, C. M., and Sharp, J. T. (1974). Antivascular antibody. Ann. rheum. Dis., 33, 371-375.

Rizzetto, M. and Doniach, D. (1973). Types of 'reticulin' antibodies detected in human sera by immunofluorescence. J. clin. Path., 26, 841-851.

Strickland, R. G. and Hooper, B. (1972). The parietal cell heteroantibody in human sera: prevalence in a normal population and relationship to parietal cell autoantibody. Pathology, 4, 259-263.

Szulman, A. E. (1960). The histological distribution of blood group substances A and B in man. J. exp. Med., 111, 785-800.

Tagg, J. R., McGiven, A. R., and Guthrie, D. A. (1972). Heart-reactive antibodies in rheumatic fever. Med. J. Aust., 1, 621-624.

Van der Geld, H. (1964). Anti-heart antibodies in the post-pericardiotomy and the postmyocardial-infarction syndromes. Lancet, 2, 617-621. 